gặp để học máy có thể chẩn đoán được tốt hơn. Số lượng dữ liệu càng nhiều và càng phong phú thì khả năng nhận diện được tổn thương càng tốt hơn. Cơ sở hạ tầng công nghệ thông tin (CNTT) cần được đầu tư tốt để đảm bảo hiệu năng làm việc của hệ thống.

\section{TÀI LIÊU THAM KHẢO}

1. Fernandez-Millan, R., Medina-Merodio, J. A., Plata, R. B., Martinez-Herraiz, J. J., \& Gutierrez-Martinez, J. M. (2015). A laboratory test expert system for clinical diagnosis support in primary health care. Applied Sciences, 5(3), 222-240.

2. Oliveira, J., \& Proença, H. (2011), Caries detection in panoramic dental X-ray images, Computational Vision and Medical Image Processing,Springer Netherlands, 175-190.

3. Duong DL, Kabir MH, Kuo RF. Automated caries detection with smartphone color photography using machine learning. Health Informatics Journal. 2021;27(2):14604582211007530.

4. Lee JH, Kim DH, Jeong SN. Diagnosis of cystic lesions using panoramic and cone beam computed tomographic images based on deep learning neural network. Oral Diseases. 2020. 26(1):152-158.

5. Berdouses ED, Koutsouri GD, Tripoliti EE, et al. A computer-aided automated methodology for the detection and classification of occlusal caries from photographic color images. 2015;62:119-135.

6. Srivastava MM, Kumar P, Pradhan L, Varadarajan SJapa. Detection of tooth caries in bitewing radiographs using deep learning. 2017.

7. Ngan, T. T., Tuan, T. M., Minh, N. H., \& Dey, N. (2016). Decision Making Based on Fuzzy Aggregation Operators for Medical Diagnosis from Dental X-ray images. Journal of medical systems, 40(12), 280, 1-7

8. Girshick R, Donahue J, Darrell T, Malik JJItopa, intelligence $\mathrm{m}$. Region-based convolutional networks for accurate object detection and segmentation. 2016;38(1):142-158.

9. Lee H, Park M, Kim J. Cephalometric landmark detection in dental $\mathrm{x}$-ray images using convolutional neural networks. Paper presented at: Medical Imaging 2017: Computer-Aided Diagnosis2017.

\title{
BÁo CÁO SỰ Cố Y KHOA TẠI BỆNH VIỆN ĐA KHOA TỈNH PHÚ THỌ NĂM 2020
}

\section{TÓM TẮT}

Báo cáo sự cố y khoa là một vấn đề mới đối với y tế Viêt Nam, minh chứng nổi bật nhất chính là số liêu về báo cáo sự cố y khoa của nước ta được công bố còn ít hơn rất nhiếu so với các nước khác và so với thực tế nó xảy ra. Mong muốn bước đầu đưa ra những số liệu có cơ sở khoa học về vấn đề báo cáo sự cố y khoa, giúp cho công tác cải tiến chất lượng bệnh viện đa khoa tỉnh Phú Thọ nói riêng và chất lượng dịch vụ y tế nói chung cho nước nhà. Nghiên cứu mố tả cắt ngang phân tích số liệu thứ cấp là toàn bộ các báo cáo sự cố y khoa của bệnh viện từ tháng 5 năm 2019 đến tháng 4 năm 2020. Có 365 sự cố y khoa đước NVYT của bệnh viện báo cáo. Trong đó: Điều dưỡng thực hiện báo cáo 62,7\%; Cán bộ thuộc chuyển mổn khối nôi báo cáo $52,6 \%$; Hình thức báo cáo tự nguyện 97,5\%; Một số thông tin ghi nhận trong báo cáo sự cố: mô tả ngắn gọn về sự cố $100 \%$, xử trí ban đầu $87,9 \%$, khoa điều trị của người bệnh $55,6 \%$, thông báo sự cố tới người bệnh 47,7\%; ghi nhận sự cố vào hồ sơ bệnh án 23,8\%, thông báo sự

\footnotetext{
${ }^{1}$ Trung tâm y tế huyện Tân Sơn tỉnh Phú Thọ ¿Sở y tế Phú Tho

${ }^{3}$ Trường đại học Y tế công công

${ }^{4}$ Bênh viện đa khoa tỉnh Phú Tho

Chịu trách nhiệm chính: Nguyễn Huy Ngọc

Email: huyngoc888@gmail.com

Ngày nhận bài: 11.3.2021

Ngày phản biên khoa hoc: 12.5.2021

Ngày duyệt bài: 18.5.2021
}

Kiều Quang Phát ${ }^{1}$, Nguyễn Huy Ngọc $^{2}$, Nguyễn Thị Kim Ngân ${ }^{3}$, Nguyễn Quang Ần ${ }^{4}$

cố tới người nhà $14,0 \%$, thông báo sự cố tới bác sỹ $7,1 \%$. Sự cố y khoa được báo cáo là vấn đề khó của bệnh viện, báo cáo tự nguyện đã được nhân viên y tế thực hiện, thông tin trong báo cáo đa phần còn chưa đầy đủ theo yêu cầu báo cáo.

Tư khóa: Báo cáo sự cố y khoa.

\section{SUMMARY}

\section{MEDICAL INCIDENT REPORTING AT PHU THO} GENARAL PROVINCIAL HOSPITAL 2020

Medical incident reports are a new issue for Vietnamese health, the most prominent proof is that the published data on medical incident reports in our country are much less than other countries, and it is different and than it actually happens. Desiring to initially give out scientifically based data on medical incident reporting, helping to improve the quality of Phu Tho province general hospital in particular and the quality of medical services in general for our country. The descriptive study cross-section analyzes the secondary data that are all hospital medical incident reports from May 2019 to April 2020. There are 365 medical incidents reported by the health worker of the hospital. In which: Nursing reports $62.7 \%$; Staff of internal expertise reports $52.6 \%$; Form of voluntary reporting $97.5 \%$; Some information recorded in the incident reports: brief description of the incident $100 \%$, initial management $87.9 \%$, patient's department $55.6 \%$, reporting the incident to the patient $47.7 \%$, record the incident in the medical record $23.8 \%$, report the incident to family members $14.0 \%$, report the incident to the doctor $7.1 \%$. The 
reported medical incident is a difficult problem for the hospital, the voluntary report has been done by the medical staff, the information in the report is mostly incomplete according to the reporting requirements.

Keywords: Reporting medical incidents.

\section{I. ĐĂT VẤN ĐỀ}

Báo cáo sự cỗ y khoa là việc cung cấp các thông tin về sự cố đã xảy ra hoặc có nguy cơ xảy ra trong môi trường y tế, từ đó giúp giảm thiểu sự cố tái diễn. Trên thế giới số lượng sự cố y khoa được báo cáo tại các nước là khá nhiều, Teryl K Nuckols công bố 184.166 sự cố tại một bệnh viện của Mỹ trong năm 2001, năm 2016 Martin A Makary công bố trên John Hopkin tại Mỹ có 250.000 người chết mỗi năm do sự cố y khoa, ở Anh Cousins D. H công bố từ năm 2005 đến năm 2010 đã có 526.186 báo cáo sự cố liên quan đến thuốc được báo cáo tại một bệnh viện 1500 giường bênh, tính ra trung bình cũng có 87.697 sự cố liên quan đến thuốc được báo cáo trong 1 năm, tại Trung Quốc Gao. X công bố trong giai đoạn 2012-2017, 36.498 sự cố về an toàn bệnh nhân đã được báo cáo trên môt hệ thống báo cáo của Trung Quốc xây dựng [6]. Tại Việt Nam việc báo cáo sự cố y khoa còn nhiều hạn chế mặc dù đã có những văn bản quy phạm pháp luật về vấn đề này như Thông tư số 19/2013 và Thông tư 43/2018 của Bộ Y tế, tuy nhiên việc công bố số liệu về sự cố y khoa còn chưa được rộng rãi. Năm 2018 Phan Thị Hằng công bố đánh giá thực trạng báo cáo sự cố y khoa tại bệnh viện Hùng Vương - Thành phố Hồ Chí Minh ghi nhận được 1.508 sự cố được báo cáo trong năm 2015 và 2.063 sự cố được báo cáo trong năm 2018, trong đó đối tượng báo cáo sự cố chủ yếu là điều dưỡng 38\% [4]. Năm 2019 Nguyễn Thị Thu Hà nghiên cứu và công bố có 2311 sự cố được báo cáo trong giai đoạn 20132018 tại bệnh viện Việt Nam-Thụy Điển Uông Bí Quảng Ninh, đối tượng báo cáo nhiều nhất là điêu dưỡng với $67,9 \%$, khối chuyên môn báo cáo nhiều nhất là khối nội với $29,3 \%$, hình thức báo cáo tự nguyện chiếm 99,6\%[2]. Các nghiên cứu khác tại Việt Nam về vấn đề này phần lớn chỉ dừng lại ở góc độ đánh giá kiến thức, thái độ và thực hành việc báo cáo sự cố y khoa tại các cơ sở y tế [1]. Các tác giả trong nước và trên thế giới đều ghi nhận điều dưỡng là đối tượng thực hiện các báo cáo sự cố y khoa nhiều nhất tại các cơ sở y tế và việc báo cáo sự cố y khoa cũng có những rào cản nhất định làm ảnh hưởng tới số lương và chất lượng báo cáo sư cố y khoa [1],[2],[3]. Vì những lý do trên chúng tôi tiến hành nghiên cứu đề tài này với mục tiêu là mô tả thực trạng báo cáo sự cố y khoa của nhân viên y tế bệnh viện đa khoa tỉnh Phú Thọ năm 2020.

\section{II. ĐỐI TƯợNG VÀ PHƯƠNG PHÁP NGHIÊN CứU}

Nghiên cứu định lượng: Số liệu thứ cấp báo cáo sự cố y khoa tại bệnh viện là các báo cáo sự cố y khoa trong thời gian từ 01 tháng 5 năm 2019 đến ngày 30 tháng 4 năm 2020.

Thời gian và địa điểm nghiên cứu: Từ tháng $3 / 2020$ đến tháng $8 / 2020$, tại bệnh viện đa khoa tỉnh Phú Thọ.

Thiết kế nghiên cứu: Nghiên cứu mô tả cắt ngang phân tích số liệu định lượng từ số liệu thứ cấp.

Cỡ mẫu và phương pháp chọn mẫu: Chọn toàn bộ các báo cáo sự cố y khoa được lưu trữ và quản lý tại phòng QLCL trong thời gian từ 01 tháng 5 năm 2019 đến ngày 30 tháng 4 năm 2020.

Phương pháp phân tích số liệu: Tất cả các báo cáo trên được mở, lấy thông tin để nhập vào phần mềm excel và được mã hóa phân loại sự cố theo tiêu chí trên. Nếu trong báo cáo không có thông tin theo yêu câu thì bỏ trống. Ví dụ bỏ trống trường người báo cáo nếu không có thông tin. Số liêu được chuyển sang phần mềm SPPS để thực hiện phân tích số liệu.Nghiên cứu sử dụng tần số và tỷ lệ \% để mô tả tân số của các biến trong nghiên cứu về đánh giá thực trạng báo cáo gồm: Người báo cáo, phương thức báo cáo, chất lượng thông tin của báo cáo và nội dung các sự cố được báo cáo (phân loại sự cố theo nguyên nhân, đối tượng liên quan, cách xử lý...).

Vấn đề đạo đức của nghiên cứu: Nghiên cứu được thươ hiện sau khi có sư đồng ý của Ban Giám đốc bệnh viện. Kết quả sẽ được phản hồi với Ban Giám đốc và toàn thể các khoa, phòng, trung tâm trong bệnh viện, làm cơ sở cho các giải pháp cải tiến chất lượng, nâng cao hiệu quả hoạt động báo cáo sự cố y khoa tại bệnh viện khi kết thúc nghiên cứu.

\section{KẾT QUẢ NGHIÊN CỨU}

Trong khoảng thời gian 12 tháng từ 01 tháng 5 năm 2019 đến 30 tháng 4 năm 2020 chúng tôi đã nghiên cứu toàn bộ các sự cố y khoa được báo cáo tại bệnh viện với số lượng là 365 sự cố và thu được các kêt quả sau:

3.1. Đối tượng báo cáo sự cố y khoa

Bảng 1. Đối tượng báo cáo sự cố theo chức danh chuyên mồn

\begin{tabular}{|c|c|c|}
\hline Đối tượng báo cáo & Số lượng & Tỷ lệ \% \\
\hline Điếu dưỡng & 229 & 62,7 \\
\hline Bác sĩ & 97 & 26,6 \\
\hline Khác & 5 & 1,4 \\
\hline \multicolumn{2}{|c|}{}
\end{tabular}




\begin{tabular}{|c|c|c|}
\hline Kỹ thuật viên & 4 & 1,1 \\
\hline Hộ sinh & 0 & 0,0 \\
\hline Người bệnh & 0 & 0,0 \\
\hline Người nhà người bệnh & 0 & 0,0 \\
\hline Không ghi nhận & 30 & 8,2 \\
\hline Tống số báo cáo & 365 & 100,0 \\
\hline \multicolumn{3}{|c|}{$\begin{array}{l}\text { Bảng 2. Đối tượng báo cáo theo khù } \\
\text { chuyên môn }\end{array}$} \\
\hline $\begin{array}{c}\text { Đối tượng báo cáo } \\
\text { theo khối }\end{array}$ & $\begin{array}{c}\text { Số } \\
\text { lương }\end{array}$ & $\begin{array}{c}\text { Tỷ lệ } \\
\text { \% }\end{array}$ \\
\hline Khối nôi & 19 & 52,6 \\
\hline Khối ngoại & 119 & 32,6 \\
\hline Khối phòng ban & 17 & 4,7 \\
\hline Khối cận lâm & 6 & 1,6 \\
\hline Không ghi nhân & 31 & 8,5 \\
\hline Tống số báo cáo & 365 & 100,0 \\
\hline \multicolumn{3}{|c|}{$\begin{array}{l}\text { 3.2. Hình thức báo cáo sự cố y khoa } \\
\text { Bảng 3. Hình thức báo cáo sư cố y khoa }\end{array}$} \\
\hline Hình thức báo cáo & Số lương & Tỷ lê \% \\
\hline Tư nguyên & 356 & 97,5 \\
\hline & 6 & 1,6 \\
\hline Không & 3 & 0,8 \\
\hline & 365 & 100,0 \\
\hline
\end{tabular}

3.3. Thời gian báo cáo sự cố

Bảng 4. Số báo cáo theo thời gian thứ trong tuần

\begin{tabular}{|l|l|l|}
\hline Số báo cáo theo thứ & Số lượng & Tỷ lệ \% \\
\hline
\end{tabular}

\begin{tabular}{|c|c|c|}
\hline Thứ Hai & 109 & 29,9 \\
\hline Thứ Ba & 93 & 25,5 \\
\hline Thứ Tư & 40 & 11,0 \\
\hline Thứ Năm & 38 & 10,4 \\
\hline Thứ Sáu & 57 & 15,6 \\
\hline Thứ Bảy & 4 & 1,1 \\
\hline Chủ Nhật & 6 & 1,6 \\
\hline Không ghi nhận & 18 & 4,9 \\
\hline Tống số mấu báo cáo & $\mathbf{3 6 5}$ & $\mathbf{1 0 0 , 0}$ \\
\hline
\end{tabular}

Bảng 5. Khoảng thời gian báo cáo sự cố trong ngày

\begin{tabular}{|l|l|l|}
\hline Mốc thời gian báo cáo & Số lượng & Tỷ lệ \% \\
\hline
\end{tabular}

\begin{tabular}{|c|c|c|}
\hline $0-6 h$ & 0 & 0,0 \\
\hline $6-12 \mathrm{~h}$ & 231 & 63,3 \\
\hline $12-18 \mathrm{~h}$ & 115 & 31,5 \\
\hline $18-24 \mathrm{~h}$ & 1 & 0,3 \\
\hline Không ghi nhận & 18 & 4,9 \\
\hline Tống số & $\mathbf{3 6 5}$ & $\mathbf{1 0 0 , 0}$ \\
\hline
\end{tabular}

3.4. Đặc điếm thông tin trong các sự cố được báo cáo

Bảng 6. Đăc điểm thông tin về mô tả, xử trí và đề xuất giải pháp khi găp sự cố trong các sự cố được báo cáo

\begin{tabular}{|c|c|c|}
\hline Đặc điểm thông tin & $\begin{array}{c}\text { Số } \\
\text { lượng }\end{array}$ & $\begin{array}{c}\text { Tỷ } \\
\text { lệo }\end{array}$ \\
\hline Có mô tả ngắn gọn về sự cố & 365 & 100,0 \\
\hline Có ghi rõ xử trí ban đâuu đẫ thực & 321 & 87,9 \\
\hline
\end{tabular}

\begin{tabular}{|c|c|c|}
\hline hiện & & \\
\hline $\begin{array}{c}\text { Có ghi rõ đề xuất giải pháp ban } \\
\text { đâu }\end{array}$ & 313 & 85,8 \\
\hline $\begin{array}{l}\text { Có ghi thông tin khoa điều trị của } \\
\text { người bệnh }\end{array}$ & 203 & 55,6 \\
\hline Có xác nhận tuối người bệnh & 189 & 51,8 \\
\hline Có xác nhận họ tên người bệnh & 132 & 36,2 \\
\hline Có xác nhận giới tính người bệnh & 121 & 33,2 \\
\hline Có xác nhận số hồ sơ bệnh án & 32 & 8,8 \\
\hline $\begin{array}{c}\text { Có thông báo sự cố tới người } \\
\text { bệnh }\end{array}$ & 174 & 47,7 \\
\hline $\begin{array}{c}\text { Có ghi nhận sự cố vào hồ sơ } \\
\text { bệnh án }\end{array}$ & 87 & 23,8 \\
\hline Có thông báo sự cố tới người nhà & 51 & 14,0 \\
\hline Có thông báo sự cố tới bác sỹ & 26 & 7,1 \\
\hline
\end{tabular}

\section{BÀN LUẬN}

4.1. Đối tượng báo cáo theo chức danh chuyên môn. Nhiều nhất là điều dưỡng chiếm $62,7 \%$, điều này có thể lý giải do số lượng cán bộ làm chuyên môn điều dưỡng tại bệnh viện là nhiều nhất, đối tượng này cũng làm việc trực tiếp nhiều do vậy họ gặp sự cố nhiều hớn, tuy nhiên cũng phải nói rằng nhóm này tích cực báo cáo hơn nhóm chức danh khác. Nhóm bác sỹ báo cáo chiếm $26,6 \%$ cũng là tỷ lệ tương đương với tỷ lệ bác sỹ trong toàn nhân lực bệnh viện, chứng tỏ mặc dù số liệu báo cáo chưa nhiều nhưng nhóm này cũng đã chủ động báo cáo. Đối tượng khác chiếm tỷ lệ $1,4 \%$, đây là các cán bộ thuộc khối phòng ban, cụ thể là các chức danh không thuộc chuyên môn lâm sàng nên số lượng báo cáo chưa nhiêu, cũng có thể lý giải nhóm này chỉ làm việc gián tiếp nên sự cố họ nhìn nhận được không thể nhiều như đối tượng làm trực tiếp. Đối tượng kỹ thuật viên chiếm tỷ lê $1,1 \%$, cũng là một tỷ lệ khổng cao số này chủ yếu làm kỹ thuật mà mức độ gây hại tới người bệnh ít hơn. Không có trường hợp báo cáo nào được ghi nhận là do hộ sinh, điều này được lý giải do từ tháng 3 năm 2019 khoa Sản của bệnh viện cùng khoa Nhi đã tách riêng ra Trung tâm Sản Nhi nay là bệnh viện Sản Nhi Phú Thọ hoạt động độc lập nên không ghi nhận được báo cáo trong nghiên cứu này. Sự cố người báo cáo không cung cấp thông tin chức danh có $8,2 \%$ điều này có thể lý giải một số trường hợp quên không ghi chức danh trong phiếu báo cáo, cũng có thể lý giải cũng còn một số cán bộ báo cáo sự cố chưa nghiên cứu hết các yêu cầu trong mấu báo cáo mà bỏ quên thông tin này.

Theo kết quả nghiên cứu của Nguyễn Thị Thu Hà tại bệnh viện Việt Nam-Thụy Điển Uông Bí từ năm 2013-2019 thì Điều dưỡng/Hộ sinh/Kỹ thuật 
viên là đối tượng có tỷ lệ báo cáo quản lý chất lượng cao nhất $(67,9 \%)$, báo cáo đều trong 6 năm nghiên cứu, họ cũng là đối tượng đầu tiên báo cáo sự cố trong bệnh viện (các sự cố năm 2013, 2014) [2].

Theo tác giả AbuAlRub RF và cộng sự nghiên cứu năm 2015 thì các điều dưỡng nhận thức rõ hơn về hệ thống báo cáo sự cố hơn các bác sĩ. Các bác sĩ ít có khả năng báo cáo bất kỳ sự cố nào trong 50\% hoặc nhiêu lần [5]. Năm 2015 tác giả Toyabe $s$ và cộng sự đã có nghiên cứu về báo cáo sự cố ngã của người bệnh chỉ ra là khoảng $25 \%$ các tỷ lê té ngã được ghi nhận đã không được báo cáo trong các báo cáo sự cố và bác sĩ được chứng minh là các yếu tố quan trọng liên quan đến việc không báo cáo [7].

So sánh với nghiên cứu của Trần Thị Bích Bo tiến hành 2017 tại bệnh viện Thủ Đức, nhóm bác sỹ tại bệnh viện này có thái độ tích cực báo cáo hơn nhóm điều dưỡng [1]. Theo tác giả Nguyễn Thị Kim Yến nghiên cứu năm 2015 thì nữ hộ sinh tin rằng sẽ báo cáo khi có sự cố và đã từng báo cáo từ môt sự cố cao hơn bác sĩ [4]. Số báo cáo bởi bác sỹ tại Bệnh viện đa khoa tỉnh Phú Thọ thấp hơn số báo cáo bởi Điều dưỡng thì nhiều hơn nhiều và các đối tượng khác còn rất hạn chế tương tự so với nghiên cứu của các tác giả tại các bệnh viện khác. Điều dưỡng của bệnh viện cũng có một tỷ lệ cao là các điều dưỡng đại học được đào tạo bài bản tại các trường đại học ở khu vực phía Bắc. Ho cũng là những người có thời gian bên cạnh, chăm sóc người bệnh nhiều hơn do vậy việc nắm bắt tình trạng người bệnh, diễn biến, sự cố xảy ra với người bệnh sớm hơn bác sỹ. Bác sỹ có tỷ lệ báo cáo quản lý chất lượng thấp hơn các nghiên cứu tại các bệnh viện khác bởi số lượng bác sỹ của bệnh viện không cao so với tiêu chuẩn nhân lực của Bô y tế, thời gian tiếp xúc trực tiếp với người bệnh ít hơn so với điều dưỡng.

4.2. Đối tượng báo cáo theo khối chuyên môn. Nhân viên y tế khối nội có số lượng báo cáo vượt chội so với cán bộ của các khối khác, tiếp đển là khối ngoại, và đặc biệt khối phòng ban là khối làm gián tiếp lại có số lượng báo cáo nhiều hơn cả khối cận lầm sàng. Mặc dù số lượng cán bộ của khối Nội chỉ nhiều hơn khối Ngoại khoảng 5\%, nhưng số lượng sự cố được báo cáo thì nhiều hơn hẳn, điêu này không nói lên được rằng khối nôi nhiều sự cố hơn mà có thể do cán bộ của khối nội quan tâm nhiều hơn về việc báo cáo sự cố y khoa. Theo nghiên cứu của Phạm Đức Mục, Lương Ngọc Khuê, Margaret Chen và một số tác giả khác, thì sự cố y khoa xảy ra nhiều ở nơi liên quan tới phẫu thuật, tuy nhiên trong nghiên cứu này số lượng sự cổ được khối ngoại báo cáo ít hơn hẳn của khối nội, chứng tỏ việc báo cáo sự cố y khoa của khối ngoại còn chưa đúng với thực tế vốn có của nó. Theo quy định của bệnh viện thì: Người báo cáo sự cố y khoa là người gây ra sự cố hoặc người phát hiện, chứng kiến sự cố. Sự cố có thể xảy ra tại đơn vị mình hoặc phát hiện ở đơn vị khác trong bệnh viện. Số liệu phòng quản lý chất lượng báo cáo phần lớn là sự cố y khoa từ các khoa, phòng trong bệnh viện liên quan đến chức năng giám sát, phát hiện vấn cần cải tiến chất lượng trong bệnh viện của phòng quản lý chất lượng và bao gồm cả sự cố của phòng như thực hiện sai, thực hiện chưa đúng quy trình, quy định của Bộ y tế, bệnh viện... Mặt khác, nhân viên phòng quản lý chất lượng còn có cả yếu tố nêu gương trong báo cáo quản lý chất lượng. Căn cứ vào số liệu báo cáo sự cố của từng khoa, phòng, đơn vị trong bệnh viện nhận thấy số khoa thuộc khối nội thực hiện công tác báo cáo sự cố nhiều hơn hẳn các khoa, đơn vị thuộc khối ngoại 18/12 (số đơn vị nội/ngoại của bệnh viện là: 23/12), điêu này chứng tỏ đã có $100 \%$ các khoa lâm sàng khối ngoại đã thực hiện báo cáo, còn các khoa lâm sàng khối nội chỉ có 18/23 khoa có báo cáo, trong khi đó chỉ có một khoa cận lâm sàng thực hiện việc báo cáo sự cố đó là khoa chẩn đoán hình ảnh, vậy câu hỏi ở đây là các khoa cận lâm sàng khác liệu có xảy ra sự cô hay không? Hay sự cố xảy ra không được ghi nhận, không được báo cáo.

4.3. Hình thức báo cáo sự cố y khoa. Trong số các sư cố được báo cáo thì hình thức tự nguyện được ghi nhận nhiều nhất tới gần $97,5 \%$ các sự cố, trong số các sự cố bắt buộc phải báo cáo đều đúng theo quy định của Bộ y tế. Kết quả này của chúng tôi tương đồng với nghiên cứu của Nguyễn Thị Thu Hà với $99 \%$ là báo cáo tự nguyện, và phần lớn báo cáo trong nghiên cứu của Lê Thanh Tùng là báo cáo tự nguyên, các tác giả khác như Trần Thị Bíc Bo, Nguyễn Thị Mỹ Linh, Nguyễn Thị Kim Yến, Sinclair, Bond cũng cho nhận định tương tự $[1],[2],[4]$.

\subsection{Vấn đề thời gian báo cáo sự cố}

- Thời gian báo cáo theo các thứ trong tuần: Nhận thây thời gian báo cáo vào ngày Thứ Hai trong tuần của các báo cáo của bênh viên đa khoa tỉnh Phú Thọ chiếm nhiều nhất với tỷ lệ $29,9 \%$, Thứ Tư là ngày có ít báo cáo nhất với $1,1 \%$ sự cố được ghi nhận vào ngày này. Nhận định về vấn đề này cho thấy có lẽ sự liên quan tới 
chu kỳ làm việc của bệnh viện, trong đó đặc biệt là việc nắm bắt việc triển khai các công việc của bệnh viện thông thường trong buổi giao ban chiều thứ sáu toàn viện có việc thông báo các nội dung yêu cầu trong tuần tới, ngoài ra còn có báo cáo và các khuyến cáo về việc thực hiện việc báo cáo sự cố y khoa theo hướng dẫn của Bộ y tế. Do vậy sáng ngày thứ 2 khi giao ban các khoa, phòng, đơn vị thường phổ biến lại để cán bộ nắm bắt và triển khai, có lẽ vì thế nên sự cố được báo cáo nhiều hơn vào ngày thứ hai tại bệnh viện đa khoa tỉnh Phú Thọ. Tác giả Nguyễn Thị Thu Hà nghiên cứu thấy thời gian báo cáo theo thứ đồng đều giữa các ngày trong tuần. Các nghiên cứu trong và ngoài nước chưa tìm thấy có nghiên cứu nào nói tới vấn đề này [2],[4],[6].

- Khoảng thời gian báo cáo được thực hiện trong ngày: Cung giờ từ $6-12 \mathrm{~h}$ là cung giờ báo cáo được thực hiện nhiều nhất, điều này chứng tỏ cán bộ đã ý thức được việc báo cáo ngay từ bắt đầu khoảng thời gian làm việc trong ngày. Tiếp theo là cung giờ buổi chiều, chỉ có 1 sự cố được báo cáo ở cung giờ 18-24h và không có sự cố nào được báo cáo trong khoảng thời gian từ 0-6h. Qua đây nhận thấy việc báo cáo sự cố của cán bộ chưa thực sự thường trực. Thông thường công việc chuyên môn tại bệnh viện thường ít hơn vào buổi chiều, tuy nhiên qua đây thêm nhận định về việc báo cáo sự cố chưa chắc có sự liên quan tới số lượng công việc. Vấn đề này cũng chưa được ghi nhận trong các nghiên cứu được tham khảo.

4.5. Đặc điểm thông tin trong các sự cố được báo cáo. Thông tin được cán bộ báo cáo thực hiện đầy đủ nhất đó là mô tả ngẳn gọn về sự cố với tỷ lệ $100 \%$ các sự cố có thông tin này, đây là việc rất quan trọng nhằm giúp cho bộ phận đầu mối phân tích được tình huống, điều này chứng tỏ các cán bộ thực hiện báo cáo đã rất quan tâm tới tính huống xảy ra sự cố. Tác giả Nguyễn Thị Thu Hà cho biết trong nghiên cứu của mình thông tin này được cung cấp tới 99,6\%, các tác giả Dương Minh Đức, Nguyễn Thi Kim Yến, Nguyễn Thị Thu, Trần Thị Bích Bo cũng cho kết quả phỏng vấn cán bộ nhận thức về việc phải mô tả tình huống tới $100 \%$. Các thông tin đề xuất giải pháp ban đầu và giải pháp đã thực hiện cũng được các báo cáo ghi khá đầy đủ tới $85-87 \%$ các sự cố, điều này chứng tỏ việc sự cố xảy ra đã được cán bộ rất để tâm vào việc xử trí ngay và rất có ý thức báo cáo lại nội dung này. Tỷ lệ này trong các nghiên cứu của các tác giả trong nước cũng rất cao Nguyễn Thị Thu Hà tới $99 \%$... Riêng các thông tin khác cần cung cấp thì kết quả của chúng tôi tỷ lệ cung cấp đầy đủ còn thấp trong đó có việc xác nhận sự cố vào hồ sơ bệnh án và báo cho bác sỹ được ghi nhận rất thấp, chỉ 7-9\% số sự cố được ghi nhận thông tin này. Điều này chứng tỏ các sự cố xảy ra thường được nhân viên chủ động xử trí mà chưa có sự báo cáo và ghi nhận lại vào căn cứ điều trị cho người bệnh, đây cũ̃ng là một trong các lý do mà sự cố xảy ra ít ghi nhận được trên hồ sơ bệnh án. Về việc thông báo sự cố tới người bệnh và người nhà cũng khác nhau trong khi có $47,7 \%$ sự cố được thông báo tới người bệnh thì trong số đó chỉ có $14 \%$ sự cố được thông báo tới người nhà, điều này qua PVS có một số cán bộ cho rằng khi có sự cố xảy ra cân giải thích trước tiên cho người bệnh để người bệnh hợp tác sau mới tới người nhà. Các thông tin khác cũng không được báo cáo một cách đầy đủ trong phiếu báo cáo. Nguyễn Thị Thu Hà nghiên cứu thấy việc báo cáo các thông tin này trong nghiên cứu của mình là khá cao tới $99 \%$ sự cố có ghi nhận vào hồ sơ và $25 \%$ sự cố được thông báo cho người nhà. Các tác giả khác trong nước cũng chưa thấy công bố số liệu này. Năm 2015 tác giả Mira JJ và cộng sự nghiên cứu trên 1087 chuyên gia y tế, chỉ có 430 chuyên gia y tế $(39,6 \%)$ đã thông báo cho người bệnh về một lỗi/một sự cô xảy ra [2],[4],[8].

\section{KẾT LUÂ̂N}

Trong vòng 12 tháng của năm 2019 và năm 2020 bệnh viện ghi nhận được 365 sự cố y khoa được báo cáo do nhân viên y tế tự nguyện báo cáo. Một số kết luận chính về thực trạng báo cáo sự cố y khoa trong nghiên cứu chúng tôi xin được tóm tắt như sau: Báo cáo sự cố y khoa là vấn đề khó tại bệnh viện đa khoa tỉnh Phú Thọ; Điều dưỡng là đối tượng thực hiện báo cáo 62.7\%;Cán bộ thuộc chuyên môn khối nội có số lượng báo cáo $52.6 \%$;Báo cáo tự nguyện $97.5 \%$; Thời gian báo cáo vào ngày Thứ Hai $29.9 \%$; Thông tin cung cấp trong báo cáo sự cố phần lớn chưa đầy đủ, trong đó mô tả ngắn gọn về sự cố trong phiếu báo cáo $100 \%$.

\section{TÀI LIỆU THAM KHẢO}

1. Trần Thị Bích Bo (2017), "Nghiên cứu về kiến thức hành vi thái độ của nhấn viên y tế về báo cáo sự cố y khoa tại bệnh viện Thủ Đức năm 2017", Luận văn thạc sỹ.

2. Nguyến Thị Thu Hà (2019), "Thực trang báo cáo sự cố y khoa và một số yểu tố ảnh hưởng tại bệnh viện Việt Nam - Thụy Điển Uông Bí giai đoạn 2013-2019". Luaân văn thạc sỹ quản lý bệnh viện.

3. Phan Thị Hằng (2018), "Đánh giá thực trạng báo cáo sự cố y khoa tại bệnh viện Hùng Vương - 
Thành phố Hồ Chí Minh", Diễn đàn QLCL- Cục Quản lý KCB lần thứ 4.

4. Nguyển Thị Kim Yến (2015), "Nghiên cứu phân tích hành vi báo cáo sự cố y khoa tại bệnh viện Từ Dũ", Luân văn thac sỹ.

5. R. F. AbuAlRub, N. A. Al-Akour, N. H. Alatari (2015), "Perceptions of reporting practices and barriers to reporting incidents among registered nurses and physicians in accredited and nonaccredited Jordanian hospitals", J Clin Nurs.
24(19-20), tr. 2973-82

6. X. Gao, et al (2019), "Implications from China patient safety incidents reporting system", Ther Clin Risk Manag. 15, tr. 259-267.

7. S. Toyabe (2015), "Characteristics of Inpatient Falls not Reported in an Incident Reporting System", Glob J Health Sci. 8(3), tr. 17-25.

8. J. Mira et al (2014), "Hospital Reputation and Perceptions of Patient Safety", Medical Principles and Practice. 23(1), tr. 92-94.

\title{
TÌNH TRANG KIÊTT SỨC VÀ MộT SỐ YẾU TỐ LIÊN QUAN ĐẾN TÌNH TRANG KIẸT SỨC CỦA NHÂN VIÊN CHẨN ĐOÁN HİNH ẢNH TẠI BỆNH VIỆN HỮU NGHI VIỆT TIỆP - HẢI PHÒNG NĂM 2020
}

\author{
Nguyễn Bảo Trân ${ }^{1}$, Nguyễn Thị Thu Hương1, \\ Phạm Minh Khuế, Vũ Hải Vinh ${ }^{2}$
}

\section{TÓM TẮT}

Nghiên cứu cắt ngang mô tả nhằm mục đích nghiên cứu tình trạng kiệt sức và các yếu tố liển quan đến tình trạng kiệt sức của nhân viên chẩn đoán hình ảnh tại Bệnh viện Hữu nghị Việt Tiệp, Hải Phòng. Kết quả nghiên cứu cho thây tỷ lệ nhân viên bi kiêt sức cao là $20,2 \%$, trung bình là $32,9 \%$ và thấp là $46,9 \%$. Mức đô kiêtt sức của đối tượng nghiên cứu ở mức đô trung bình $(3,09 \pm 1,42)$. Theo đặc điểm cá nhân, yếu tố ảnh hưởng nhiều đến tình trang kiệt sức của nhân viên là số ngày trực trong tuần $(\beta=0,45 ; p=0,001)$. Một số yếu tố ảnh hưởng một phân đến tình trang kiệt sức của nhân viên như tuổi hay trình độ chuyền môn, thời gian công tác. Yếu tố giới không ảnh hưởng đến tình trang kiệt sức của nhân viên chẩn đoán hình ảnh.

Từ khóa: burnout, kiệt sức, nhân viên chẩn đoán hình ảnh

\section{SUMMARY \\ BURNOUT AND RELATED FACTORS OF RADIOLOGISTS IN VIET TIEP HOSPITAL, HAI PHONG - VIETNAM 2020}

This research aimed to study burnout and factors related to burnout state of radiologists in Viet Tiep general hospital, Hai Phong. The study results showed that the percentage of employees suffering from burnout was high at $20.2 \%$, the average was $32.9 \%$ and the low was $46.9 \%$. The exhaustion level of study subjects was moderate $(3.09 \pm 1.42)$. According to personal characteristics, the most influential factor affecting employee exhaustion is the number of days on duty per week $(\beta=0.45 ; p=0.001)$. Some factors partly affect the exhaustion of employees such as age

1 Trường Đại Học Y Dược Hải Phòng

${ }^{2}$ Bệnh viện Hữu Nghi Việt Tiệp, Hải Phòng

Chịu trách nhiệm chính: Nguyến Bảo Trân

Email: nbtran@hpmu.edu.vn

Ngày nhận bài: 10.3 .2021

Ngày phản biên khoa hoc: 10.5.2021

Ngày duyệt bài: 17.5.2021 or qualifications, working time. Gender does not affect the radiologist's exhaustion.

Keywords: burnout, exhaustion, radiology

\section{I. ĐẶT VẤN ĐỀ}

Thuật ngữ "burnout" được nhà tâm lý học người Mỹ Freudenberger đưa ra vào năm 1974 [1]. Ông sử dụng nó để mô tả hậu quả của việc căng thẳng nghiêm trọng và kiệt sức là một khái niệm trong căng thẳng nghề nghiệp. Kiệt sức nghề nghiệp là tình trạng căng thẳng kéo dài liên quan đến công viêc.

Bộ công cụ thường được sử dụng để đo lường tình trạng kiệt sức là Maslach Burnout Inventory (MBI). Trong đó Maslach Burnout Inventory - General Survey (MBI-GS) [2] là thang đo được sử dụng rộng rãi để nghiên cứu tình trạng kiệt sức trên nhiêu môi trường làm việc và văn hóa khác nhau.

Tất cả các ngành nghề đều có thể gặp tình trạng kiệt sức, nhưng một số nghề nhất định có nguy cơ rõ rệt như nghề chăm sóc sức khỏe [3]. Sự tiếp xúc liên tục giữa nhân viên y tế và bệnh nhân với các vấn đề tâm lý, thể chất và xã hôi liên quan của ho có thể khiến đối tương này bi căng thẳng nhiều hơn so với các nghề khác và dễ bi kiệt sức [3]. Do đó, cần có thêm các cuộc điều tra về mức độ phổ biến của tình trang kiệt sức trong ngành nghề này. Hầu hết các nghiên cứu đã được thực hiện về tỷ lệ kiệt sức của các bác sỹ, điều dưỡng, bác sỹ và kỹ thuật viên xạ trị $[4,5]$. Ngoài ra, kết quả của các nghiên cứu khác cho thây một số yếu tố như tuổi tác, giới tính, giờ làm việc mỗi tuần và kinh nghiệm làm việc đóng vai trò quan trọng trong mức độ kiệt sức trong nghề nghiệp [6]. 